\title{
Evaluating Uncertain Income Streams under a Regime-Switching Process
}

\author{
Yungchih George Wang ${ }^{1}$ \\ ${ }^{1}$ Department of International Business \\ National Kaohsiung University of Applied Sciences, Taiwan
}

\begin{abstract}
This paper extends the dynamic programming, utility maximization model proposed by Wang (2004) to value an investment opportunity whose income streams follows a regime-switching process in incomplete markets. Specifically, the model is applied to solve for certainty equivalent of an investment opportunity in a two-regime, five-branch lattice. The application is then expanded to a more general case of multi-nodes and multi-regimes. The finding indicates that investor's risk attitude is a non-trivial factor in investment decision-making. When the investor is more risk-averse, the certainty equivalent of an investment opportunity is shown to be lower. Numerical analysis also reveals that the inverse relationship between certainty equivalent and risk attitude is less sensitive when the market is less incomplete. Finally, the application of valuing an investment opportunity whose project value follows a discrete regime-switching process has been successfully integrated into the utility maximization model.
\end{abstract}

Keywords: dynamic programming, regime-switching process, incomplete markets, certainty equivalent

\section{Introduction}

The main obstacle of valuation present in incomplete markets is that not all contingent claims are attainable ${ }^{1}$. For this reason, Wang (2004) suggested a discrete dynamic programming framework for evaluating uncertain income streams, generated from an investment opportunity in incomplete markets, in the form of certainty equivalents (CE). He shows that the value of income streams may be obtained by deriving

\footnotetext{
${ }^{1}$ A contingent claim is said to be attainable when there exists a trading strategy which can replicate the payoffs of the contingent claim at all times by an asset or a portfolio. (See Pliska, 1997, p.17)
}

the $\mathrm{CE}$ either from the buying price approach or the selling price approach. ${ }^{2}$

This paper further extends the dynamic programming, utility maximization model proposed by Wang to value an investment opportunity whose income streams follows a regime-switching process. Specifically, the model is applied to solve for certainty equivalent of an investment opportunity in a tworegime, five-branch lattice. The application is then expanded to a more general case of multi-nodes and multi-regimes.

\section{Research Purposes}

Along the line of various utility maximization models in Smith and Nau (1995), and Smith (1998), Wang suggests a dynamic programming, utility maximization framework for evaluating income streams generated from an investment opportunity in incomplete markets. Unlike the earlier integrated models, Wang demonstrates a general case which allows for both market uncertainty and private uncertainty to be resolved in utility maximization.

Since income streams of an investment opportunity may actually obey different distributions of regime, it is thus non-trivial to direct the research to the case of concern. Earlier regime-switching option models such as Bollen (1998) appear to be limited in valuing an investment opportunity whose payoffs cannot be replicated with existing marketed securities. We then integrate the utility maximization framework into Bollen's two-regime, pentanomial lattice. Therefore, the research purposes of this research project are as follows:

\footnotetext{
${ }^{2}$ The buying price is defined as the lump-sum present payment, made by the buyer, which makes expected utility with the project equal to expected utility without the project. The selling price is referred to as the added-in certainty equivalent, received by the seller, which makes expected utility without the project equal to expected utility with the project. See Smith and Nau (1995).
} 
1. To propose a general asset pricing framework which integrates utility maximization and regimeswitching features. The technique of discrete dynamic programming will be applied to solve for recursive structures for pricing an investment opportunity in incomplete markets.

2. To develop numerical techniques for the ease of computation. In addition, the numerical techniques are expected to demonstrate the unique martingale price in complete markets and the value range of certainty equivalents in incomplete markets.

3. To address the applications of the framework by conducting a numerical analysis.

\section{Literature Review}

\subsection{Pricing in Incomplete Markets}

Complete markets, by definition, describe the situation where the payoffs of the focus asset can be perfectly replicated or 'spanned' by a single marketed asset (also called a twin asset) or an equivalent portfolio of securities. The replicating portfolio approach originates from the seminal studies by Black and Scholes (1973) and Merton (1973) in valuing European options in continuous time. Yet, empirical evidence suggests that financial markets in the real world are incomplete to investors due to transaction costs and other trading frictions (Aiyagari, 1993), the misspecification of trading models, the difficulty of estimating input parameters, and the infeasibility of delta hedging (Figlewski, 1998).

The main obstacle of valuation present in incomplete markets is that not all contingent claims are attainable, and even when they are, there may exist no unique price for the contingent claims. El-Karoui and Quenez (1995) address this valuation problem in incomplete markets, arguing that by arbitrage the price of the claim must lie between two bounds, the infimum and the supremum.

To deal with market incompleteness, financial economists such as Brennan and Schwartz (1982) and Cox, Ingersoll, and Ross (1985) suggest adjusting the drift rate of each stochastic process by an amount of a process-specific risk premium where the risk premium is derived from the equilibrium model of financial markets. With the adjustment of the drift rate, the market can be seen as if it is complete. Taking a different view, most researchers focus on searching for highly correlated marketed assets.

\subsection{Regime-Switching Process}

As mentioned earlier, a regime-switching process is characterized by the underlying asset with two or more stochastic processes from different data-generating probability distributions. Regime-switching models have been widely applied to explain economic behaviors in interest rates (Dahlquist and Gray, 1995) and exchange rates (Engle and Hamilton, 1990; Engle and Hakkio, 1996). Literature on regime-switching models associated with options mostly centers on discontinuous information arrival leading to jumps (Naik, 1993) or capability of random switching among various distributional regimes (Gray, 1996; Bollen, 1998).

\section{Research Methodology}

\subsection{Dynamic Programming}

Assume that a finite sample space, $\Omega$, exists with $k(k<\infty)$ elements, $\Omega=\left\{\omega_{1}, \omega_{2}, \cdots, \omega_{k}\right\}$, where $\omega$ denotes the state of the world. All the investment and consumption behavior takes place at time $t=\{0,1, \cdots, T\}$. There is a probability measure $P$ on $\Omega$, with $P(\omega) \geq 0$ for all $\omega \in \Omega$ and $\sum_{i=1}^{k} P\left(\omega_{i}\right)=1$. $S$ denotes a security price process, $S=\left\{S_{t}^{n}: t=0,1, \cdots, T ; n=0,1, \cdots, N\right\}$, where $S$ is a security matrix and $S_{t}^{n}$ is a scalar representing the price of security $n$ at time $t$. Among all the securities, $S^{0}$ denotes a risk-free security vector while the others denote risky security vectors. Let $\theta$ be a vector of trade strategies, $\theta=\left\{\theta_{t}^{n}: t=0,1, \cdots, T ; n=0,1, \cdots, N\right\}$, in the investor's portfolio where the scalar $\theta_{t}^{n}$ represents the units of security $n$ held between time $t$ and $t+1$ and the scalar $\theta_{t}^{0}$ is the dollar amount invested in $S_{t}^{0}$ from time $t$ to $t+1$ at a risk-free rate, $r$. In addition, $x$ denotes a security return process, $x=\left\{x_{t}^{n}: t=0, \cdots, T ; n=0, \cdots, n\right\}$, where $x_{t}^{n}$ is the return of security $n$ from time $t-1$ to time $t$.

Investor's wealth is denoted by a value process, $V=\left\{V_{t}: t=0,1, \cdots, T\right\}$, which represents the total value of the portfolio at time $t$. The consumption plans, $C=\left\{C_{t}: t=0,1, \cdots, T\right\}$, are a non-negative stochastic process with $C_{t}$ representing the amount of funds consumed by the investor at time $t$. Note that the consumption process is admissible when $C_{t} \leq V_{t}$. Also, at the end of the intended time horizon, all the terminal wealth is consumed so that $C_{T}=V_{T}$. Suppose there is a process of cash streams, $H=\left\{H_{t}: t=0, \cdots, T\right\}$ where $H_{t}(\omega)$ denotes income streams at time $t$ and state $\omega$. Therefore, the wealth, $V_{t}(\omega)(\forall \omega \in \Omega, t \geq 1)$, can be expressed as follows:

$$
\begin{aligned}
V_{t}(\omega)= & \left(V_{t-1}-C_{t-1}\right)(1+r)+\theta_{t-1} S_{t}(\omega)\left[x_{t}(\omega)-r\right] \\
& +H_{t}(\omega), \forall \omega \in \Omega
\end{aligned}
$$


where $r$ is risk-free rate and $x_{t}(\omega)=\frac{S_{t}(\omega)-S_{t-1}}{S_{t-1}}$.

Suppose the investor's objective is to maximize his/her expected utility over terminal wealth $\left(V_{T}\right)$. To simplify the analysis, we let $\alpha$ denote the amount of money invested in the risky security, i.e., $\alpha=\theta S$, $X$ be the matrix of excess return of risky stocks, i.e., $X=x-r$, and $A$ be the coefficient of the investor's risk attitude $(A>0)$. The utility maximization problem can be formulated as follows:

$$
\begin{aligned}
& \max _{\alpha_{0}^{*}, \alpha_{1}^{*}, \cdots, \alpha_{T-1}^{*}} E_{0}\left[-\exp \left(-A V_{T}\right)\right] \\
& \text { s.t. } V_{t}=(1+r) V_{t-1}+\alpha_{t-1}^{*} X_{t}+H_{t}, t=1, \cdots, T
\end{aligned}
$$

By recursive optimizations for multi-periods, the temporal value function for any time period $t$ can be expressed as

$$
J_{t}^{*}=\beta_{t}^{*}\left[-\exp \left(-A \lambda_{t} V_{t}\right)\right]
$$

where $\beta_{t}^{*}=E_{t}\left(K_{t+1}^{*} \beta_{t+1}^{*}\right) \quad, \quad \beta_{T}^{*}=1 \quad, \quad$ and $\lambda_{t}=(1+r)^{T-t}$.

Next, the same utility maximization problem needs to be solved without income streams in the budget constraints. The recursive structures are exactly the same with the asterisk * removed. By equating the value functions at time $0, J_{0}$ and $J_{0}^{*}$, the certainty equivalent, denoted by $C E$, of the investment opportunity is shown as follows:

$$
C E_{t}=\frac{1}{A \lambda_{t}}\left[\ln \left(\frac{\beta_{t}}{\beta_{t}^{*}}\right)\right]
$$

\subsection{Discrete Regime-Switching Model}

Suppose there are $\psi$ possible regimes in the world. The underlying variable therefore evolves as a random-switching process according to a risk-adjusted transition probability matrix which objectively reflects regime-switching uncertainty. It is important to note that the conditional transition probability matrix may differ if there is a time variation. The conditional transition probability matrix between time $t-1$ and $t$ is expressed as follows:

$$
\Pi_{t}=\left[\begin{array}{cccc}
\pi_{t}^{11} & \pi_{t}^{12} & \cdots & \pi_{t}^{1 \psi} \\
\pi_{t}^{21} & \pi_{t}^{22} & \cdots & \pi_{t}^{2 \psi} \\
\vdots & \vdots & \vdots & \vdots \\
\pi_{t}^{\psi 1} & \pi_{t}^{\psi 2} & \cdots & \pi_{t}^{\psi \psi}
\end{array}\right]
$$

where $\pi_{t}^{i j}=P\left(R E_{t}=j \mid R E_{t-1}=i\right)$ denotes the transition probability from regime $i\left(R E_{t-1}=i\right)$ to regime $j\left(R E_{t}=j\right)$, and $\sum_{j=1} \pi_{t}^{i j}=1, \forall i=1,2, \cdots, \psi$.
The certainty equivalent at time $t$, conditional on regime $i$, is thus a weighted average of certainty equivalents at time $t+1$ with the weights drawn from the transition probability matrix:

$$
E\left(\left.C E_{t}\right|_{R E_{t}=i}\right)=\sum_{j=1}^{\psi} \pi_{t}^{i j} E_{t}\left(\left.C E_{t}\right|_{R_{t+1}=j}\right), \forall i=1, \cdots, \psi
$$

It is then important to specify the starting probabilities at time zero. Let $\pi_{0}^{1}, \pi_{0}^{2}, \cdots, \pi_{0}^{\psi}$ be the starting probabilities at time zero for all the regimes. The certainty equivalent at time zero can be expressed as follows:

$$
E\left(C E_{0}\right)=\sum_{i=1}^{\psi} \pi_{0}^{i} E\left(\left.C E_{0}\right|_{R_{1}=i}\right)
$$

\section{Numerical Analysis}

In the numerical analysis, we assume that the means of both regimes are $5 \%$, and that the standard deviations of high volatility regime and low volatility regime are $50 \%$ and $20 \%$, respectively. The two-period recombining pentanomial lattice indicating both security price dynamics and project payoffs is displayed in Figure 1. We assume that the current security price is $\$ 20$, the risk-free rate is $5 \%$, and $\Delta t$ is one year. The starting probability for the high volatility regime is 0.5 , which means that the starting probability for the low volatility regime is also 0.5 . The transition probability is assumed to be constant over time and is $\Pi=\left[\begin{array}{cc}0.35 & 0.65 \\ 0.4 & 0.6\end{array}\right]$

The corresponding probabilities for five nodes from top to bottom are assumed to be $0.4259,0.3955$, $0.3267,0.2778$, and 0.5741 , respectively. The resulting certainty equivalent of the investment opportunity is presented in Figure 2, which indicates a negative NPV for all the degrees of risk aversion.

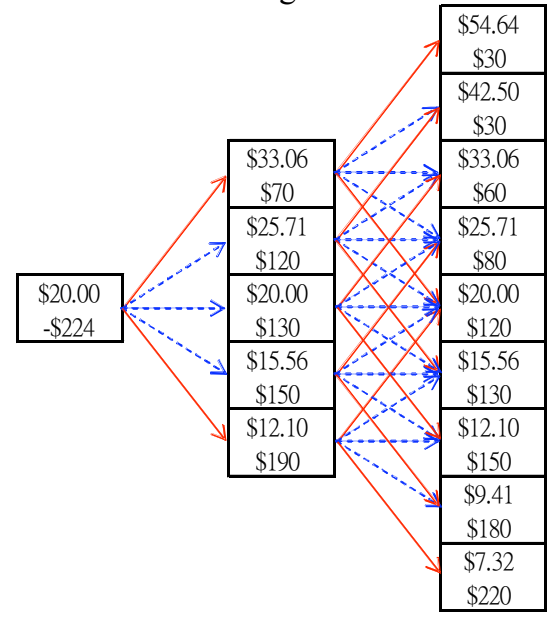

Fig. 1: The Investment Opportunity in a Regime-Switching Pentanomial Lattice 


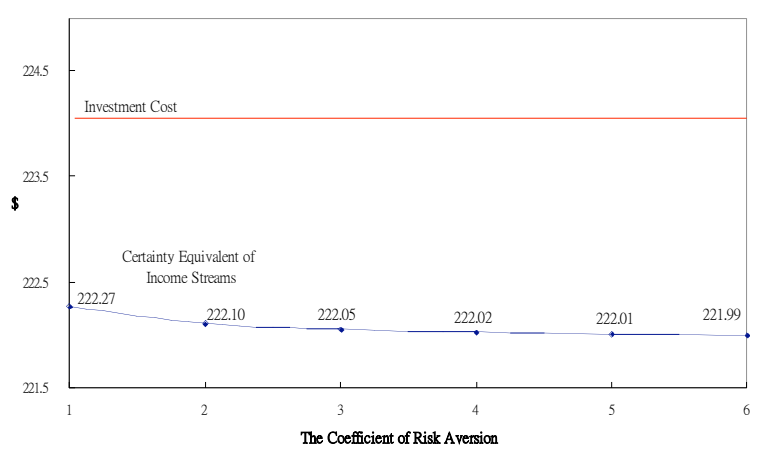

Fig. 2: The Wealth Effects under the 'Invest' and 'Decline' Alternatives

\section{Conclusion}

In this paper, it is found that the investor's risk preference may play an influential role in the investment decision-making process through the determination of certainty equivalents. When the investor is more risk-averse, the certainty equivalent of an investment opportunity is shown to be lower. It is also found that that when the project is near at-themoney, risk attitude is more crucial in making investment decisions. When one is less risk-averse than the indifferent investor, he tends to accept the project, and vice versa. The preceding examples demonstrated also reveal that the inverse relationship between certainty equivalent and risk attitude is less sensitive when the market is less incomplete. Finally, the application of valuing an investment opportunity whose project value follows a discrete regimeswitching process has been successfully integrated into the utility maximization model.

\section{References}

[1]. Aiyagari, S. Rao. "Explaining Financial Market Facts: the Importance of Incomplete Markets and Transaction Costs." Federal Reserve Bank of Minneapolis Quarterly Review 17, 1 (1993), 17-31.

[2]. Black, Fisher and Scholes, Myron "The Pricing of Options and Corporate Liabilities." Journal of Political Economy 81 (1973), 637-659.

[3]. Bollen, Nicolas P. "Valuing Options in RegimeSwitching Models." Journal of Derivatives 6 (1998), 38-49.

[4]. Brennan, Michael J., and Schwartz, Eduardo S. "Consistent Regulatory Policy under Uncertainty." Bell Journal of Economics 13, 2 (1982), 506-521.

[5]. Brennan, Michael J., and Schwartz, Eduardo S.
"Evaluating Natural Resource Investments." Journal of Business 58 (1985), 135-157.

[6]. Copeland, Tom, Koller, Tim, and Murrin, Jack Valuation: Measuring and Managing the Value of Companies. McKinsey \& Company, Inc. (2000), New York.

[7]. Cox, John, Ross, Stephen, and Rubinstein, Mark. "Option Pricing: A Simplified Approach." Journal of Financial Economics 7 (1979), 229263.

[8]. Dahlquist, M. and Gray, S. F. "Regimeswitching and interest rates in the European Monetary System." Working Paper, Duke University (1995).

[9]. Dixit, Avinash K. and Pindyck, Robert S. Investment under Uncertainty. Princeton University Press (1994). Princeton, New Jersey.

[10]. El-Karoui, Nicole and Quenez, Marie-Claire. "Dynamic Programming and Pricing of Contingent Claims in Incomplete Markets." SIAM Journal on Control and Optimization 33, 1 (1995), 29-66.

[11]. Elton, Edwin J. and Gruber, Martin J. "Dynamic Programming Applications in Finance." Journal of Finance 26 (1971), 473-506.

[12]. Engle, C. and Hakkio, C. S. "The Distribution of Exchange Rates in the EMS." International Journal of Finance and Economics 15 (1996), 55-67.

[13]. Engle, C. and Hamilton, J. D. "Long Swings in the Dollar: Are They in the Data and do Markets Know it?" American Economic Review 80, 4 (1990), 689-713.

[14]. Figlewski, Stephen. "Derivatives Risks, Old and New." Brookings-Wharton Papers on Financial Services 1 (1998), 159-217.

[15]. Gray, Stephen F. "Modeling the Conditional Distribution of Interest Rates as a RegimeSwitching Process." Journal of Financial Economics 42 (1996), 27-62.

[16]. Harrison, J. Michael and Kreps, David M. "Martingales and Arbitrage in Multiperiod Securities Markets." Journal of Economic Theory 20 (1979), 381-408.

[17]. Hayes, Robert H. and Garvin, David A. "Managing as if Tomorrow Mattered." Harvard Business Review 60 (1982), 71-79.

[18]. Hodder, James E. and Riggs, Henry E. "Pitfalls in Evaluating Risky Projects." Harvard Business Review 63 (1985), 128-135. 
[19]. Howard, Ronald A. "Proximal Decision Analysis." Management Science 17 (1971), 507-541.

[20]. Majd, Saman and Pindyck, Robert S. "Time to build, Option Value, and Investment Decisions." Journal of Financial Economics 18 (1987), 7-27.

[21]. Mason, Scott P. and Merton, Robert C. "The Role of Contingent Claims Analysis in Corporate Finance." Recent Advances in Corporate Finance, E Altman and M. Subrahmanyam, ed. (1985), 7-54. Irwin. Homewood, Illinois.

[22]. McDonald, Robert and Siegel, Daniel. "The Value of Waiting to Invest." Quarterly Journal of Economics 101 (1986), 707-728.

[23]. Myers, Stewart C. "Finance Theory and Financial Strategy." Midland Corporate Finance Journal 5 (1987), 6-13.

[24]. Naik, Vasanttilak. "Options Valuations and Hedging Strategies with Jumps in the Volatility of Asset Returns." Journal of Finance 48, 5 (1993), 1969-1984.

[25]. Pennings, Enrico and Lint, Ono. "The Option Value of Advanced R\&D." European Journal of Operational Research 103 (1997), 83-94.

[26]. Pindyck, Robert S. "Irreversibility, Uncertainty, and Investment." Journal of Economic Literature 29 (1991), 1110-1148.

[27]. Pliska, Stanley R. Introduction to Mathematical Finance (1997). Blackwell, MA, USA.

[28]. Raiffa, Howard. Decision Analysis: Introductory Lectures on Choices under Uncertainty (1968). Addison-Wesley, MA, USA.

[29]. Smith, James E. "Evaluating Income Streams: A Decision Analysis Approach." Management Science 44 (1998), 1690-1708.

[30]. Smith, James E. and Nau, Robert F. "Evaluating Risky Projects: Option Pricing Theory and Decision Analysis." Management Science 41 (1995), 795-816.

[31]. Trigeorgis, Lenos. "Valuing the Impact of the Uncertain Competitive Arrivals on Deferrable Real Investment Opportunities.” Working Paper, Boston University (1990).

[32]. Trigeorgis, Lenos, and Mason S. P. "Valuing Managerial Flexibility." Midland Corporate Finance Journal 5 (1987), 14-21.

[33]. Wang, George Y. "Topics in Investment Appraisal and Real Options." Unpublished PhD
Thesis, Imperial College Library and University of London Library (2004). 